\title{
Utilization and management of irrigation water for sustainable farming of Macadamia nuts in Piesanghoek cropland in Limpopo Province, South Africa
}

\author{
F. I. Mathivha, P. M. Kundu, J. O. Odiyo \& R. Makungo \\ University of Venda, Department of Hydrology and Water Resources, \\ South Africa
}

\begin{abstract}
Utilization and management of irrigation water is essential for sustainable farming. The Macadamia cropland in Piesanghoek cropland falls in the arid to semi-arid climatic zone in Limpopo Province of South Africa. It is estimated that irrigated agriculture accounts for $62 \%$ of all the water used in South Africa and in many instances, its use is highly inefficient. A few farmers have adopted new computerized technologies for irrigation management but many still use conventional irrigation methods, which are not based on crop water requirements, leading to poor water utilization and low irrigation efficiencies. This study evaluated the Piesanghoek Macadamia cropland to determine the irrigation scheduling schemes for efficient utilization and management of water. Soil samples were analysed for particle size distribution and bulk density while field tests were carried out to determine infiltration rates on the cropland, after which geostatistical tools in ArcGIS were used to show the spatial variability. The South Africa Plant Water (SAPWAT) model was used to automate the irrigation scheduling. The results showed that the supply and availability of soil moisture was of fundamental importance to plant growth and crop production. It also showed that changes in the soil moisture stored in the root-zone were due to differences between the inputs and outputs from this zone. An irrigation efficiency of $80 \%$ was achieved and it was observed that the Macadamia trees did not use as much water as the SAPWAT model prescribed.

Keywords: crop water requirement, efficient utilisation, geostatistical tools, Macadamia, SAPWAT.
\end{abstract}




\section{Introduction}

Surface water resources generated by runoff are estimated to be about $53500 \mathrm{~m}^{3} /$ year in South Africa and Lesotho, while the groundwater resources are estimated to range from a maximum of $47727 \mathrm{~m}^{3} /$ annum to as low as $7536 \mathrm{~mm}^{3} /$ annum (South Africa Consulate General, [1]). Irrigated agriculture accounts for $62 \%$ of all the water used in South Africa and, in many instances, its use is highly inefficient (Department of Water Affairs and Forestry, [2]). The suitability of land for irrigation depends on soil characteristics, soil profile, geological deposits and surface texture. Evaluation of soil infiltration characteristics and determination of the final steady infiltration rate are required for increased irrigation water use efficiency (Haghighi et al. [3]). To achieve efficiency, a number of infiltration models including physical models such as that of Green-Ampt, Philip and empirical models such as Horton [4] are used to estimate the final infiltration rates. Irrigation scheduling by water balance approach is based on estimating soil water balance (Broner [5]). Using the soil water balance equation, one can identify periods of water stress or excesses, which may have adverse affect on crop performance. This identification will help in adopting appropriate management practices to alleviate the constraint and increase the crop yields. Reference evapotranspiration provides a base for calculating specific crop evapotranspiration at any stage in the growth cycle. For efficient water utilization and irrigation water management, geostatistical tools can be used to model and predict the spatial distribution of infiltration and hydraulic conductivity, which are the most important parameters for achieving irrigation efficiency. Geostatistical tools use the variogram structure which consists of the nugget (the variance at zero lag distance), sill (the variance to which the variogram asymptotically rises), and decorrelation length (range of spatial dependence). The SAPWAT model (Crosby and Crosby [6]) is a model that is available to estimate crop water requirements of a variety of crops in South Africa. Van Heerden et al. [7] used the SAPWAT model to estimated irrigation requirement in the Orange-Vaal and Orange-Riet water users association. Woyessa et al. [8] used the model to assess water management in Sand-Vet irrigation scheme in South Africa. The two studies showed that it was possible to carry out an irrigation requirement planning for an area, and provide reliable information that would contribute towards an integrated water management system.

\section{The study area}

The Piesanghoek Macadamia cropland shown in Figure 1 is located in the upper Luvuvhu River catchment. It lies between latitudes $23^{\circ} 1^{\prime} 48^{\prime \prime S}$ and $23^{\circ} 4^{\prime} 48^{\prime \prime} \mathrm{S}$ and longitudes $30^{\circ} 6^{\prime} 0^{\prime \prime} \mathrm{E}$ and $30^{\circ} 6^{\prime} 36^{\prime \prime} \mathrm{E}$ and measures approximately 136 ha. The cropland is found in the quaternary catchment A91A at the foot hills of the Soutpansberg Mountain range as shown by the panoramic view in Figure 2. The soils vary between sandy soils, sandy loam and silt loam soils. Luvuvhu River is the major perennial river upon which most farmers rely for irrigation purposes. 
The mean annual rainfall in the area varies from 200 to $1500 \mathrm{~mm}$ although the bulk of the catchment receives less than $500 \mathrm{~mm} /$ year. Rainfall occurs during the summer months of October to April with some occasional rainfall being received during the winter months.

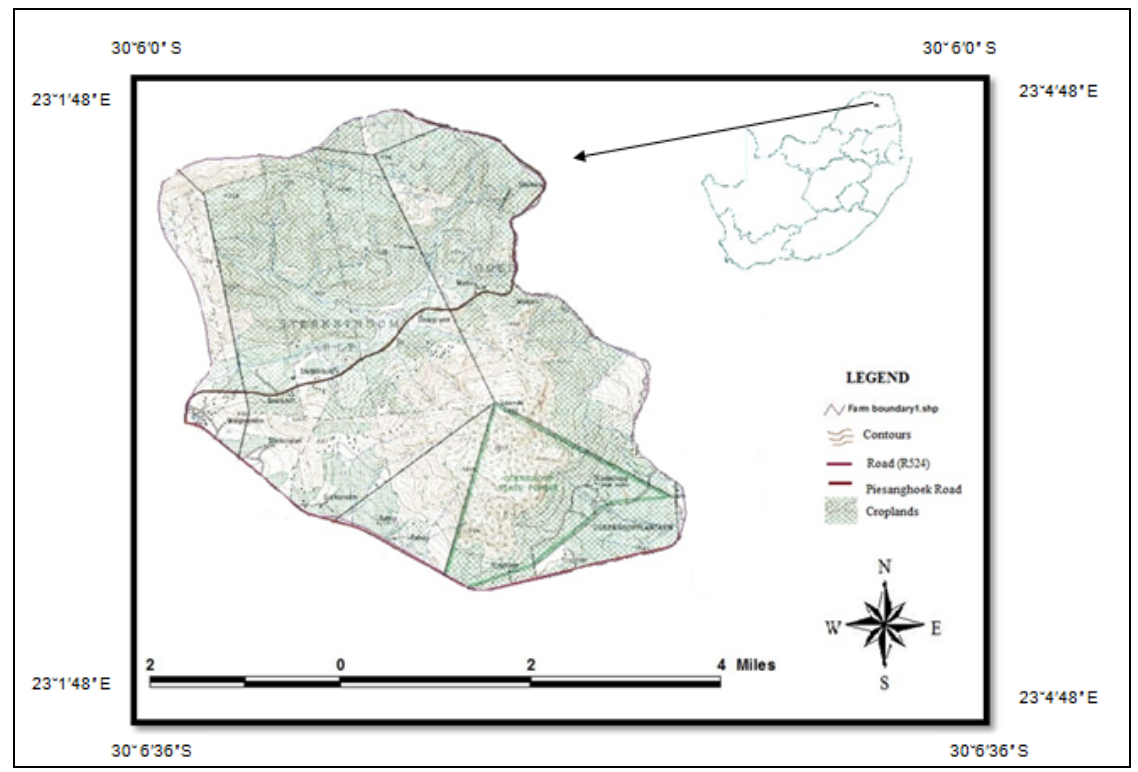

Figure 1: The study area.

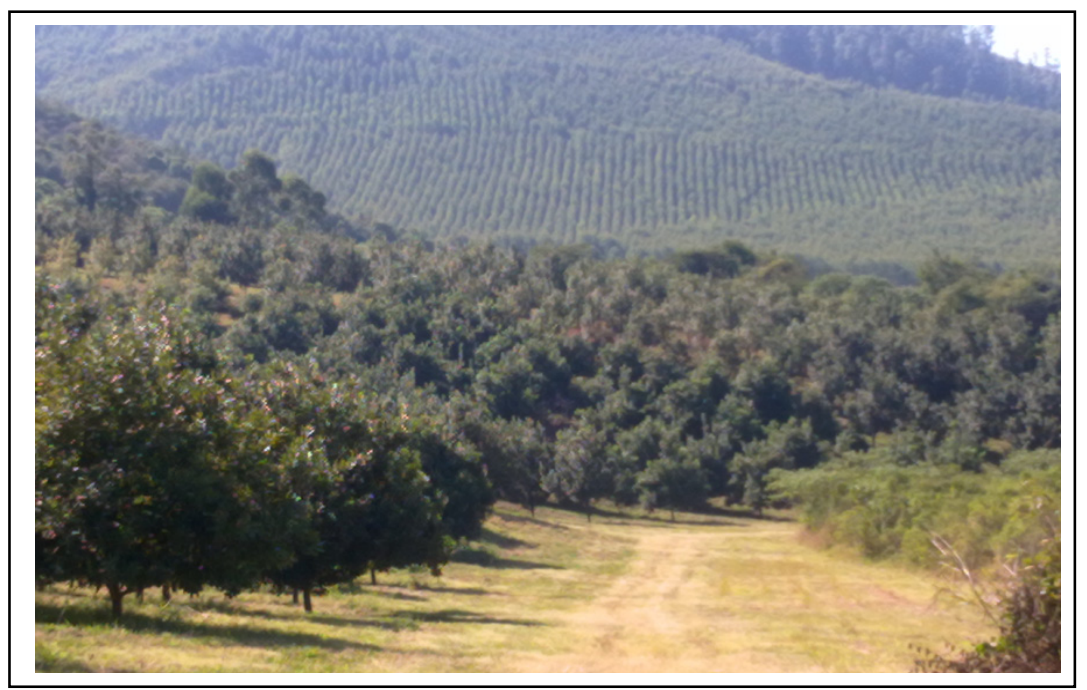

Figure 2: A view of Piesanghoek Macadamia cropland (Photo by Mathivha, 2012). 


\section{Materials and methods}

\subsection{Soil data}

Soil samples were collected at three random points around the infiltrometer by augering at $0-30 \mathrm{~cm}, 30-60 \mathrm{~cm}, 60-90 \mathrm{~cm}$ and $90-1000 \mathrm{~cm}$ depth. One set was used for initial soil moisture determination while the other was used for soil texture analysis using a mechanical sieve shaker with sieves of between $4 \mathrm{~mm}$ to $0.2 \mathrm{~mm}$ sieve mesh. The samples for determining the bulk density were collected using sampling cores. To determine the initial soil moisture, the soil samples were placed in a drying oven, at $105^{\circ} \mathrm{C}$ for 24 hours, after which the soil was removed from the oven and weighed. The weight of the container was subtracted from both the weight of moist soil and dry soil to determine the percentage of the initial soil moisture content.

To determine the particle size distribution, the mass of soil retained on each sieve was obtained by subtracting the weight of the empty sieve from the mass of the sieve plus retained soil, and this mass was recorded as the weight retained on the data sheet. The percent retained on each sieve was obtained by dividing the weight retained on each sieve by the original sample mass. Percentage passing (or percent finer) was calculated by starting with $100 \%$ and subtracting the percent retained on each sieve as a cumulative procedure. A semi-logarithmic graph plot of grain size versus percent finer was then made. The USDA textural triangle showing the soil texture of Piesanghoek Macadamia croplands was plotted using D-Plot computer software.

To determine the soil bulk density, samples were weighed and placed in the oven at $105^{\circ} \mathrm{C}$ for 24 hours and their volume calculated using the internal dimension of the core. Bulk density was dependent on soil moisture, soil texture and organic matter particles, as well as their packing arrangement.

\subsection{Infiltration rates}

Infiltration rates were determined in situ using a double ring infiltrometer as described by Bertrand [9]. Tests were carried out on three different topographical locations at selected sites, which constituted of a valley bottom, sloping land and the hill top. The tests were run for two hours and once the values were constant, the basic infiltration rate had been reached. A curve was then established to make it possible to determine how long it would take to infiltrate a certain amount of water.

\subsection{Spatial variability of infiltration rates}

This study was conducted to determine whether spatial and temporal variations in soil infiltration characteristics had any impact on the performance of micro sprinkler irrigation and thereafter identify appropriate management strategies that could account for the variability and substantially improve irrigation performance. In this study the average distance between adjacent in-situ soil moisture sites was $100 \mathrm{~m}$. The elements of each variogram model and the 
regression coefficient $r^{2}$ of the fitting procedure were determined. The model with the higher value of $r^{2}$ was selected as an appropriate model to represent the sample semi-variogram. The scatterplot of tail versus head values for a certain lag, $\boldsymbol{h}$, is usually called an $\boldsymbol{h}$-scattergram. With $N(\boldsymbol{h})$ representing the number of pairs separated by lag $\boldsymbol{h}$, the statistics for lag $\boldsymbol{h}$ were computed using eqns (1) to (3) below:

$$
\text { Covariance: } \begin{aligned}
C(\mathbf{h})= & \frac{1}{N(\mathbf{h})} \sum_{\alpha=1}^{N(\mathbf{h})} z\left(\mathbf{u}_{\alpha}\right) \cdot z\left(\mathbf{u}_{\alpha}+\mathbf{h}\right)-m_{0} \cdot m_{+\mathbf{h}} \\
C(\mathbf{h}) &
\end{aligned}
$$

$$
\text { Correlation: } \rho(\mathbf{h})=\frac{C(\mathbf{h})}{\sqrt{\sigma_{0} \cdot \sigma_{+\mathbf{h}}}}
$$

$$
\text { Semivariance: } \gamma(\mathbf{h})=\frac{1}{2 N(\mathbf{h})} \sum_{\alpha=1}^{N(\mathbf{h})}\left[z\left(\mathbf{u}_{\alpha}+\mathbf{h}\right)-z\left(\mathbf{u}_{\alpha}\right)\right]^{2}
$$

where $m_{0}$ and $m_{+h}$ are the means of the tail and head values:

$$
m_{0}=\frac{1}{N(\mathbf{h})} \sum_{\alpha=1}^{N(\mathbf{h})} z\left(\mathbf{u}_{\alpha}\right) \quad m_{+\mathbf{h}}=\frac{1}{N(\mathbf{h})} \sum_{\alpha=1}^{N(\mathbf{h})} z\left(\mathbf{u}_{\alpha}+\mathbf{h}\right)
$$

and $\sigma_{0}$ and $\sigma_{+h}$ are the corresponding standard deviations:

$$
\sigma_{0}=\frac{1}{N(\mathbf{h})} \sum_{\alpha=1}^{N(\mathbf{h})}\left[z\left(\mathbf{u}_{\alpha}\right)-m_{0}\right]^{2} \quad \sigma_{+\mathbf{h}}=\frac{1}{N(\mathbf{h})} \sum_{\alpha=1}^{N(\mathbf{h})}\left[z\left(\mathbf{u}_{\alpha}+\mathbf{h}\right)-m_{+\mathbf{h}}\right]^{2}
$$

\subsection{The SAPWAT model}

The SAPWAT model was used for automated irrigation scheduling using the calculated inputs. It utilizes a reference evapotranspiration that provides a base for calculating specific crop evapotranspiration at any stage in the growth cycle. It is defined as the quantity of water transpired by plants during their growth or retained in the plant tissue, plus the moisture evaporated from the surface of the soil and the vegetation, expressed in depth of water loss or used in the specified 
time. Reference evapotranspiration was calculated using the Penman-Monteith eqn (4) shown below.

$$
E T_{o}=\frac{0.408 \Delta\left(R_{n}-G\right)+\gamma \frac{900}{T+273} u_{2}\left(e_{s}-e_{a}\right)}{\Delta+\gamma\left(1+0.34 u_{2}\right)}
$$

where, $\mathrm{ET}_{\mathrm{o}}$ is the reference evapotranspiration in $(\mathrm{mm} / \mathrm{day}), \mathrm{R}_{\mathrm{n}}$ is the net radiation of the crop surface in $\left(\mathrm{MJ} / \mathrm{m}^{2} /\right.$ day), $\mathrm{G}$ is the soil heat flux density $\left(\mathrm{MJ} / \mathrm{m}^{2} /\right.$ day $), \mathrm{T}$ is the mean daily air temperature at $2 \mathrm{~m}$ height in $\left({ }^{\circ} \mathrm{C}\right), \mathrm{u}_{2}$ is the windspeed at $2 \mathrm{~m}$ height in $(\mathrm{m} / \mathrm{s}), e_{s}$ is the saturation vapour pressure in $(\mathrm{kPa})$, $e_{a}$ is the actual vapour pressure in $(\mathrm{kPa}),\left(e_{s}-e_{a}\right)$ is the saturation vapour pressure deficit in $(\mathrm{kPa}), \Delta$ is the slope vapor curve in $\left(\mathrm{kPa} /{ }^{\circ} \mathrm{C}\right)$ and $\gamma$ is the psychtometric constant in $\left(\mathrm{kPa} /{ }^{\circ} \mathrm{C}\right)$.

In the process of calculating the irrigation requirement of crops by SAPWAT the conventional application efficiency, which is made up of water loses (runoff from the farm, leakage out of pipes or canals) and distribution uniformity coefficient was taken into consideration. The crop factors are based on the FAO four stages of crop development (Allen et al. [10]) and are interpolated to provide monthly values. Default values are provided for all crops grown under irrigation in South Africa. Irrigation method and management are dependent on factors such as soil type, rooting depth, water content of the soil at the commencement of the season, frequency and amount of irrigation, planting date, and crop and varieties grown.

\section{Results and discussion}

\subsection{Soil texture}

The soil in the study area is dominated mostly by sandy soil as shown on the textural triangle in Figure 3 by the triangular symbol. Most of the triangles fall in the textural class of sandy loam which consist of 7 to $25 \%$ clay, more than $52 \%$ sand, and the percentage of silt plus twice the percentage of clay is 30 or more while the circles fall in the textural class of silt loam which consists of $50 \%$ or more silt and 12 to $27 \%$ clay, or 50 to $80 \%$ silt and less than $12 \%$ clay. Although the two farms are within close proximity, they seem to show a slight difference in the soil texture. However both textural classifications are dominated by sand and loam textures. These soils are well drained because the dominant soils are sandy and loamy, and therefore favourable for Macadamia nuts.

\subsection{Bulk density}

The bulk density ranged from $1.32 \mathrm{~g} / \mathrm{m}^{3}$ to $1.75 \mathrm{~g} / \mathrm{m}^{3}$ with an average of $1.54 \mathrm{~g} / \mathrm{cm}^{3}$ which was ideal for macadamia plant growth in a sandy soil texture since the recommended value should be $<1.60 \mathrm{~g} / \mathrm{cm}^{3}$. High bulk density is an 


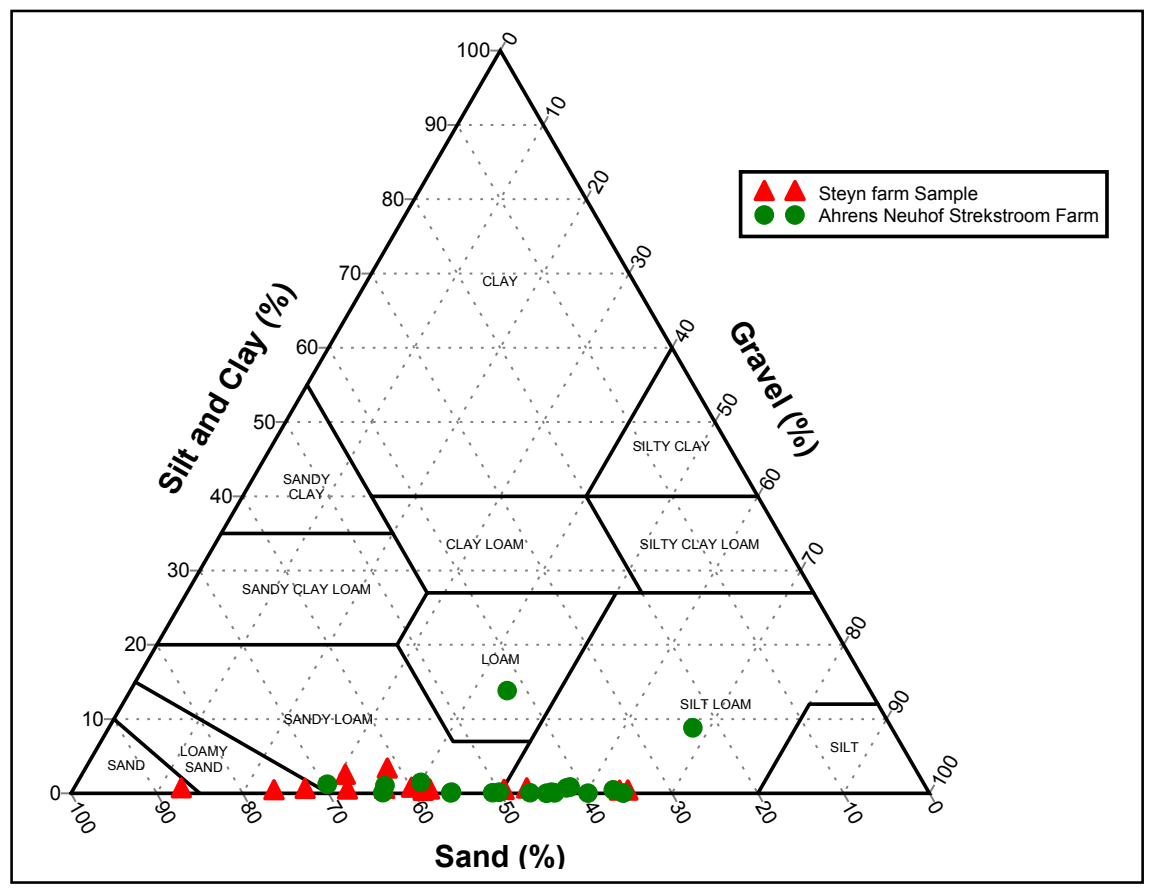

Figure 3: $\quad$ Soil texture for Piesanghoek Macadamia croplands.

indicator of low soil porosity and soil compaction. Soil bulk density that is $>1.80 \mathrm{~g} / \mathrm{cm}^{3}$ restricts plant roots development and creates conditions for poor water and air movement in the soil. Compaction can result in shallow plant rooting and poor plant growth, influencing crop yield and reducing vegetative cover available to protect soil from erosion (Arshad et al. [11]).

\subsection{Infiltration rates}

The field measured infiltration rates increased rapidly at the start of the test but later decreased to approach a constant value. This was so because the soil pores filled continuously as time elapsed. The initial soil moisture content ranged from $18.1436 \%$ to $37.2740 \%$. The average infiltration rate was found to be $13.91 \mathrm{~mm} / \mathrm{hr}$ for most of the farm.

\subsection{Spatial variability of infiltration rates}

Figure 4 shows the spatial variability of infiltration rates for Piesanghoek Macadamia croplands. The rates were lower where the mean soil moisture values were higher after precipitation events with higher variance being observed during wet periods after precipitation. This was due to spatially varying soil hydraulic properties creating differential infiltration rates during wet periods following rainfall, and causing larger variation in soil moisture. The variation also appeared 
to follow the landscape, whereby lower values were in the depressions while higher values were on sloping land and hill tops. Smaller variation would be observed during dry periods where soil-related variability becomes minimal.

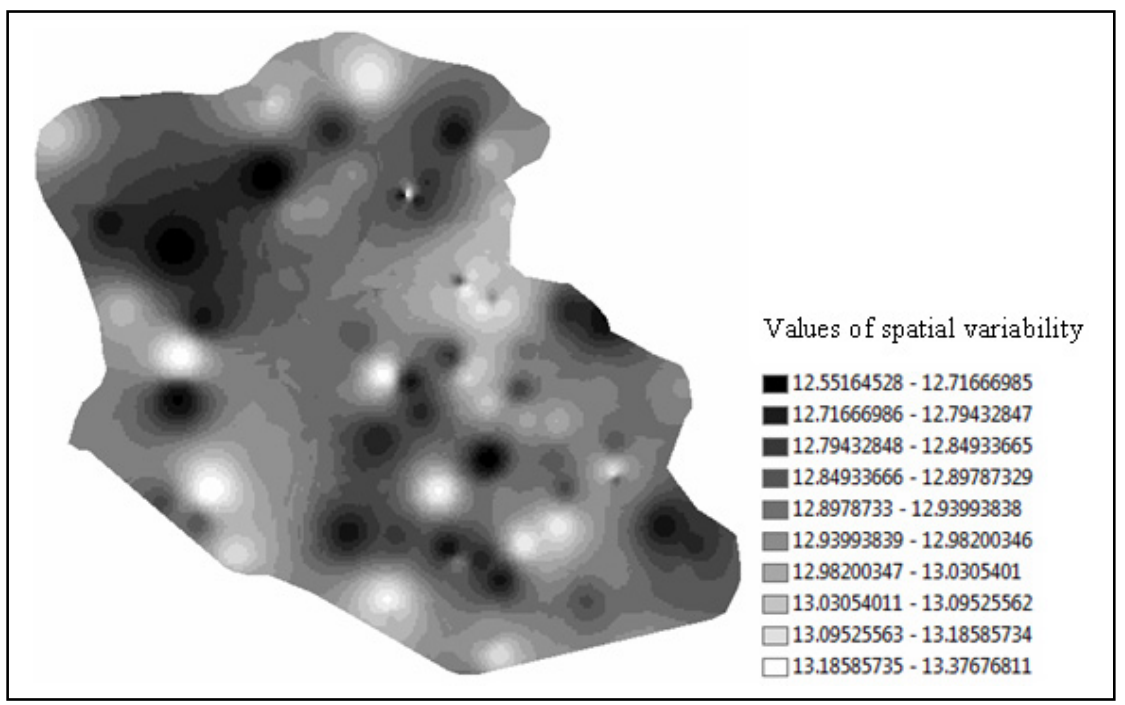

Figure 4: Spatial variability of infiltration rates.

\subsection{Irrigation water availability}

Water harvesting from rainfall forms an integral part of irrigation water in the study area. The daily rainfall data from Louis Trichard-Levubu weather station showed that more rainfall was received during the summer months of November to March. This however did not translate to more water being available for the crop. Due to high temperatures during these months, more water was lost through evaporation. In such cases farmers resorted to harvested water in farm ponds and groundwater from boreholes.

\subsection{The SAPWAT model}

The model determined all factors necessary for automated irrigation scheduling. The crop factor was influenced by different irrigation methods and production practices such as the time between irrigation, ground cover at full growth stage and the wetted area.

\subsubsection{Reference Evapotranspiration (ETo)}

SAPWAT calculated the average daily reference evapotranspiration values. The $\mathrm{ET}_{0}$ values for Louis Trichard varied from $2.5 \mathrm{~mm} /$ month to $3.3 \mathrm{~mm} / \mathrm{month}$ during the winter months of May to August. During the summer months evaporation varied between $3.3 \mathrm{~mm} / \mathrm{month}$ and $5.9 \mathrm{~mm} / \mathrm{month}$. Figure 5 shows a plot of macadamia evapotranspiration which is equivalent to CWR. It showed that more water was required during the summer months to meet the 
evapotranspiration requirement of the crop. The highest water requirement was during the months of January in which the highest temperatures on a hot day can reach $40^{\circ} \mathrm{C}$, resulting in an increased evaporation which directly affects the crop evapotranspiration.

\section{Crop Evapotranspiration [mm]}

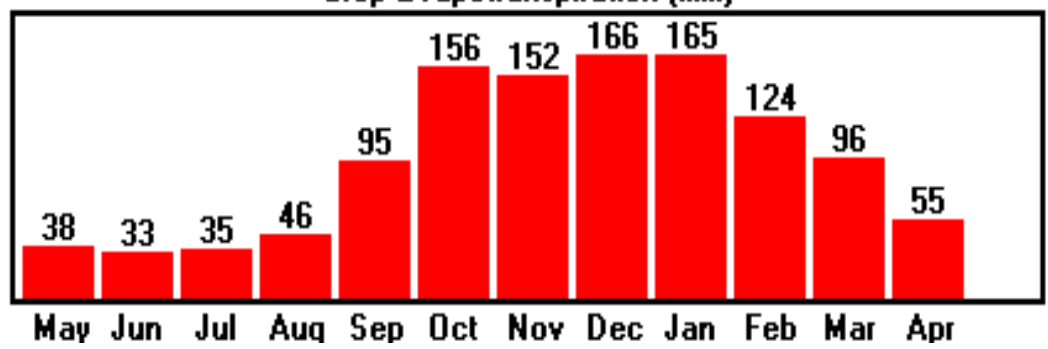

Figure 5: Average monthly crop evapotranspiration for Macadamia Intergrifolia in Piesanghoek Macadamia croplands.

\subsubsection{Estimation of crop irrigation requirements}

SAPWAT estimated the crop irrigation requirement based on crop evapotranspiration, where the effective rainfall was calculated using the Soil Conservation Service method as described by Burman and Allen, cited by Van Heerden et al. [7]. The irrigation requirement took into account irrigation efficiency and yield targets. Figure 6 shows the irrigation requirements for macadamia in the study area, where it is observed that the water requirements are higher in summer as compared to winter time. Although more rainfall is received during this period, it appears that most of it lost through various processes, and hence the irrigation requirements are met through irrigation.

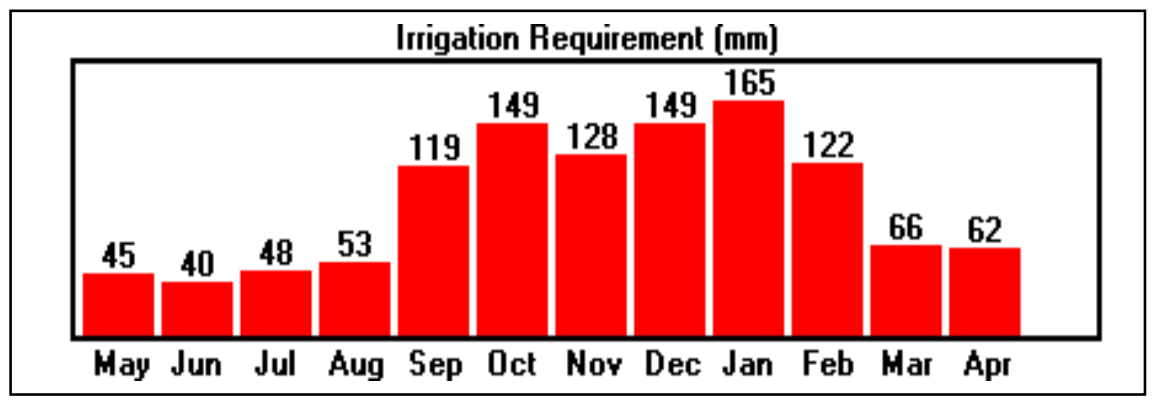

Figure 6: Average monthly crop irrigation requirement for Macadamia tree crop. 


\subsection{Utilization and management of irrigation water}

Irrigation scheduling is concerned with when to irrigate, how much to irrigate, and how to apply irrigation water. The different approaches for irrigation scheduling were based on the requirements of the SAPWAT model. Using the spatial variability of infiltration rates, it was possible to adjust the contact time needed to infiltrate the required amount of water for the different parts of the farms. The irrigation time, which is the time needed to supply the required irrigation depth depends on the stream size, the required irrigation depth and the size of the field to be irrigated. The stream size was increased to improve the distribution of water in the root zones. For the parts of the farm with sandy soils, a small stream size took a longer time before the water covered the root zone since it infiltrated rapidly into the sandy soil. Adjustments were made to meet the various soil-landscape requirements on the farms. The valley bottoms, sloping land and hill tops received different stream sizes and irrigation time. Overall, the new approach had the effect of improving the health of the macadamia trees on the hill tops which had smaller canopies and poor green leaves. The SAPWAT model prescribed a system irrigation efficiency of $80 \%$, meaning that the system now in use on Piesanghoek croplands has efficient water utilization with little wastage.

\section{Conclusions}

Field trials were carried out on Piesanghoek macadamia cropland to demonstrate the ability to estimate whole field infiltration variability, evaluate irrigation performance and optimise irrigation management taking into account the influence of spatial variability. The soil in the study area is dominated mostly by sandy soil. The results showed the impact of soil moisture levels on Macadamia production. The supply and availability of soil moisture was of fundamental importance to plant growth and crop production. Any changes in the volume of water stored in the root-zone were due to a difference between the inputs and outputs from this zone. The SAPWAT model prescribed a system irrigation efficiency of $80 \%$, meaning that the system now in use on Piesanghoek croplands has efficient water utilization with little wastage

\section{References}

[1] South African Consulate General, Water Affairs and Forestry, www.southafrica-newyork.net/consulate/wateraffairs.htm, 2007.

[2] Department of Water Affairs and Forestry, Water Conservation and Water Demand Management Strategy for the Agricultural Sector, Pretoria, South Africa, 2004.

[3] Haghighi, F., Gorji, M., Shorafa, M., Sarmadian, F. and Mohammadi, M. H., Evaluation of some infiltration models and hydraulic parameters, Spanish Journal of Agricultural Research, 8(1), pp. 210-217, 2010. 
[4] Horton, R.E., An approach towards a physical interpretation of infiltration capacity, American Journal of Soil Science Society, 5, pp. 339-417, 1940.

[5] Broner, I., Irrigation Scheduling: The Water Balance Approach, Crop series, Sate Colorado University, pp. 4, 2005.

[6] Crosby, C.T. and Crosby, C.P., SAPWAT - A Computer Program for Establishing Irrigation Requirements and Scheduling Strategies in South Africa: Executive summary, WRC Report No. 624/1/99, Pretoria, pp. 12, 1999.

[7] Van Heerden, P., Crosby, C.T. and Crosby, C.P., Using SAPWAT to estimate water requirements of crops in selected irrigation areas managed by the Orange-Vaal and Orange-Reit Water User Association, Water Research Commission, Pretoria, South Africa, Report No. TT163/01, pp. 132, 2001.

[8] Woyessa, Y.E., Pretorius, E and van Heerden, P., The application of SAPWAT Model in irrigation water management planning for the San-Vet irrigation scheme: Contribution towards an integrated catchment management system, Proc. of the 2004 Water Institute of Southern Africa (WISA), Biennial Conf., Cape Town, South Africa, pp. 1273-1279, 2004.

[9] Bertrand, A.R., Rate of water intake in the field In: Methods of Soil Analysis. Part I, 1 ed. Eds., C.A. Black et al. Agron. Monogr. 9. ASASSSA, Madison, Winscosin, USA, pp. 197-209, 1965.

[10] Allen, R.G., Pereira, L.S., Raes. D. and Smith. M., Crop evapotranspiration - Guidelines for computing crop water requirements, FAO Irrigation and drainage paper 56, Food and Agriculture (FAO) Rome, Italy, pp. 326, 1998.

[11] Arshad M.A., Lowery B., and Grossman B., Physical Tests for Monitoring Soil Quality. In: Doran J.W., Jones A.J., Methods for assessing soil quality. Madison, Wisconsin, USA. pp. 123- 141, 1996. 